\title{
OPEN Proposal for an initial screening method for identifying microplastics in marine sediments
}

\begin{abstract}
Toshiro Hata $\oplus^{1 \bowtie}$ \& Ningjun Jiang ${ }^{2}$
Marine debris, which is often called microplastics, is widespread in marine environments, particularly in sediments, and is recognized as an environmental hazard because it concentrates contaminants, forms biofilms, and sinks into marine sediments. In sediments, it may be ingested by benthos and have a negative impact on higher food chain levels. In this study, a new protocol was developed to identify microplastics in various sediment fractions. This protocol combined sieving and staining based on ordinal geotechnical/geological testing methods. The sieving process was derived from the conventional particle size distribution test, and nontoxic dyes were employed in the staining process. The protocol is safe and easy to perform as it merely involves the use of conventional geological/ geotechnical testing equipment. The new protocol was successfully employed to stain and categorize different types and sizes of microplastic particles from contaminated sediments. This safe, easy-touse, and efficient protocol can serve as the basis for a new alternative approach to study microplastics present in sediments, which can be performed using basic materials familiar to geotechnical/ geological engineers.
\end{abstract}

The 17 Sustainable Development Goals (SDGs) listed in the 2030 Agenda for Sustainable Development by the United Nations has urged the scientific community to promote a better understanding of these topics. SDG \#14 encompasses targets that consider the marine ecosystem, including marine debris. One type of marine debris, classified as microplastics, floats on the sea surface, is deposited in deep sea beds, or is stranded on the coastline, posing environmental risks to marine biota ${ }^{1,2}$. These microplastics can concentrate toxic chemicals such as organic compounds, persistent organic pollutants ${ }^{3,4}$, and trace element $s^{5,6}$ and can further increase the ecotoxicological risks from sediments. Previous research has reported that microplastics are widely deposited in shallow-to-deep seabeds. Woodal et al. reported that deep seabed sediments include microplastics that are $2-3 \mathrm{~mm}$ in length and $<0.1 \mathrm{~mm}$ in diameter ${ }^{7}$. Alomar et al. reported that shallow sediments include microplastics that are $0.063 \mathrm{~mm}$ to $>2 \mathrm{~mm}$ in diameter ${ }^{8}$. Because of their small sizes, microplastics are ingested by zooplankton and are transferred to higher food chain levels, thereby becoming harmful to marine ecosystems ${ }^{3,9}$. SDG \#14.2 focuses on achieving healthy and productive oceans, which includes evaluating the environmental impact caused by microplastic debris present in marine sediments.

Microplastics are classified into five categories based on their source: (1) direct manufacturing such as facial cleansers ${ }^{10},(2)$ subdivided or fragmented large plastic debris that has undergone degradation after exposure to the ocean environment ${ }^{11},(3)$ microfibers and textiles from garment laundry ${ }^{12,13}$, (4) synthetic rubber particles released from car tires ${ }^{14}$, and (5) disposable plastic products such as food containers and an increased production and usage of surgical face masks due to the COVID-19 pandemic ${ }^{15}$. Microplastics can contaminate sediments in coastal areas with high population densities ${ }^{9}$. Microplastics such as polyethylene (PE), polypropylene (PP), polystyrene (PS), and polyamide (PA) are commonly found in river sediments ${ }^{16}$, and PP, PE, and polyvinylchloride (PVC) are abundant in marine sediments ${ }^{11}$. PE, PP, and PS are industrial products that can spread across the sea surface easily because of their physical characteristics such as low density. Moreover, combined with natural particles such as clay, they can form biofilms. The accumulation of microorganisms on microplastics in biofilms may increase their density, accelerate their vertical transport, and cause them to sink into benthic sediments ${ }^{17}$.

To determine the environmental impacts of different types of microplastics in aquatic habitats, they should be isolated and identified. Microplastics or microfibers present in sediments are usually identified via specific gravity separations, followed by microscopic observations ${ }^{18}$. However, although isolation of microplastics via specific gravity separations can be applied to types of plastics over $1.20 \mathrm{~g} / \mathrm{cm}^{3}$, the identification of small particles

${ }^{1}$ Department of Civil and Environmental Engineering, Graduate School of Advanced Science and Engineering, Hiroshima University, 1-4-1 Kagamiyama, Higashi-hiroshima, Hiroshima 739-8527, Japan. ${ }^{2}$ Institute of Geotechnical Engineering, Southeast University, Nanjing 211189, Jiangsu, China. ${ }^{\square}$ email: thata@hiroshima-u.ac.jp 


\section{Process}

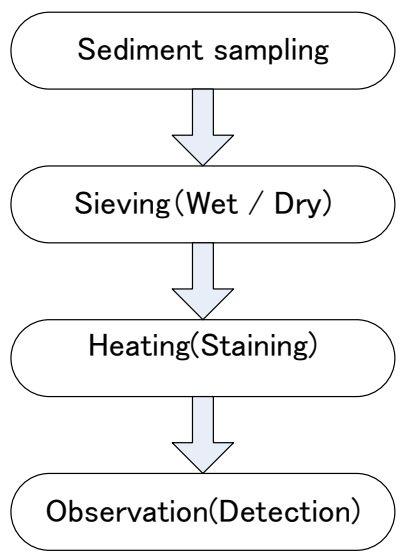

\section{Equipments}

Ekman-Birge grab

Sieve

Heat Chamber

Optical microscope

or naked eye

\section{Reference}

Figure 1. Schematic diagram of the proposed method.

and fibers using microscopes can be challenging and inefficient ${ }^{19,20}$. Fourier-transform infrared (FTIR) or Raman spectroscopy combined with microscopy are often used to study the polymer types of microplastics or microfibers, and thermogravimetric/differential thermal analysis (TGA/DTA) is used to identify the types of plastics ${ }^{21}$. However, operating these systems requires a trained technical staff with expertise in chemical analysis. To address this issue, the use of lipophilic dyes that enable the visualization of microplastics or fibers using fluorescent microscopy are recommended ${ }^{22,23}$. The advantage of this approach is that it does not require expensive analytical instruments such as FTIR and Raman spectroscopes. However, a fluorescence microscope should be used to visualize microplastics, but it is only applicable to the study of floating microplastics and those mixed with organic materials. It has low efficiency for clay-coated or sediment-contaminated microplastics. However, some researchers have developed protocols for extracting microplastics from marine sediments ${ }^{24-27}$.

Coppock et al., proposed a revised method for separating microplastics and other particles using density flotation, which can be used to recover high-density microplastics from sediments ${ }^{28}$. However, this system requires zinc chloride, which has been classified as a toxic chemical ${ }^{29}$. In the present study, we developed a safer and easier protocol for identifying sediment microplastics using conventional geological and geotechnical testing equipment with an optical microscope that is also in compliance with standardized sieving procedures from several industrial standards (Japanese Geotechnical Society [JGS] ${ }^{30,31}$, International Organization for Standardization $[\mathrm{ISO}]^{32,33}$, European Norm $[\mathrm{EN}]^{34}$, and the American Society for Testing and Materials $\left.[\mathrm{ASTM}]^{35,36}\right)$. The framework of this newly proposed method is shown in Fig. 1.

The proposed method uses basic equipment generally used for soil classification tests (particle distribution and moisture content tests) combined with a standard optical microscope used in geotechnical or geological fields. Moreover, this method does not require the use of toxic chemicals for staining the plastics and does not require extensive training. When combined with the sieving process, the microplastics in each sediment fraction could be separated and clearly identified.

The proposed method is highly efficient for detecting clay aggregate microplastic particles covered with biofilms and can detect the vertical distribution of microplastics from core samples and evaluate the relationship between particle size and adsorption or capture ability. Moreover, it can be performed using conventional (standard) laboratory instruments available at soil testing companies or educational institutions within $90 \mathrm{~min}$. This method can also promote environmental risk control with soil science or engineering activities and encourage education for younger generations, facilitating the achievement of the SDG 14 goals. In this article, we elaborate on the proposed method and demonstrate the results of its application on actual marine sediments collected at Shin-minato port at Toyama, Japan, to identify common types of microplastics.

\section{Results}

Staining color and staining of different plastic types. PP particles were stained at $105^{\circ} \mathrm{C}$ for $20 \mathrm{~min}$ using four base staining solvents (Fig. 2a). Undiluted staining solvent was used in the procedure. The four samples stained with different-color stains were collected on quantitative filter paper (retained particle size of $4 \mu \mathrm{m}$ ) using a suction filtration machine, and the staining effectiveness was evaluated via visual observation (Fig. 2b). All PP samples were stained with four non-diluted staining solvents of different colors and were easy to identify with the naked eye. However, when PP particles were mixed with sediments, most of the sediment particles stained dark, which can potentially hinder particle identification. The identification of stained microplastics mixed with natural sea sand is shown in Fig. 2c. The red-stained microplastics mixed with beach sand were easy to identify visually compared with yellow-, green-, and blue-stained microplastics.

In the second experiment, we evaluated the possibility of roughly classifying the plastic species according to the staining temperature. The relationship between the types of plastic and staining temperature under atmospheric pressure conditions is shown in Table 1. The results of the proposed method of staining the samples at 


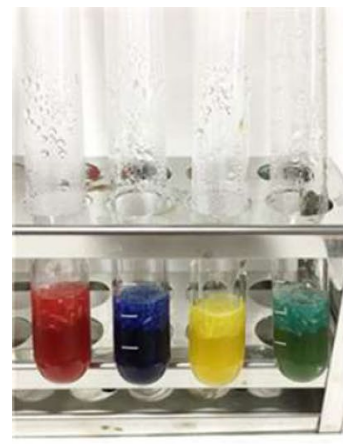

(a) Staining solvent (Basic colors)
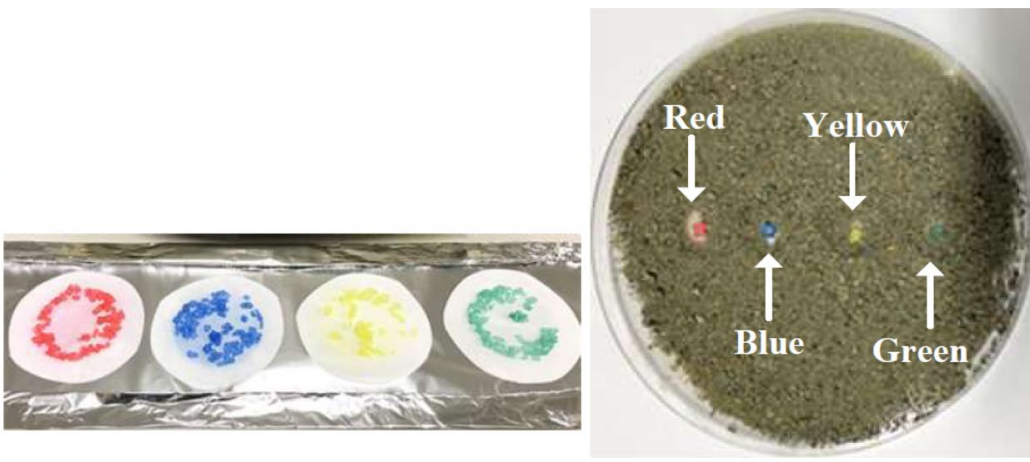

(b) Stained samples(Polypropylene)

(c) Stained PP mixed with beach sand

Figure 2. Results of staining with (a) undiluted staining solvent for polypropylene (PP), (b) 1:10 diluted staining solvent for polypropylene (PP), polyethylene (PE), and polystyrene (PS), (c) Stained PP mixed with beach sand.

\begin{tabular}{|l|l|l|}
\hline Staining temperature & Type of plastic & Comment \\
\hline Under $60^{\circ} \mathrm{C}$ & PVC & \\
\hline $60^{\circ} \mathrm{C}-80^{\circ} \mathrm{C}$ & PE, EVA, ABS, and PS & ABS: Less than $70^{\circ} \mathrm{C}$ \\
\hline $80^{\circ} \mathrm{C}$ to boiling temperature & PA, PEs, POM, PP, and PC & \\
\hline
\end{tabular}

Table 1. Relationship between the type of plastic and staining temperature under atmospheric pressure. PVC: polyvinyl chloride, EVA: Ethylene-vinyl acetate, ABS: Acrylonitrile butadiene styrene, PEs: polyester, POM: polyacetal, PC: polycarbonate.

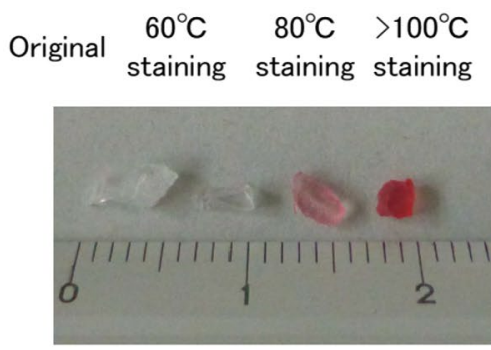

$\underline{P P}$
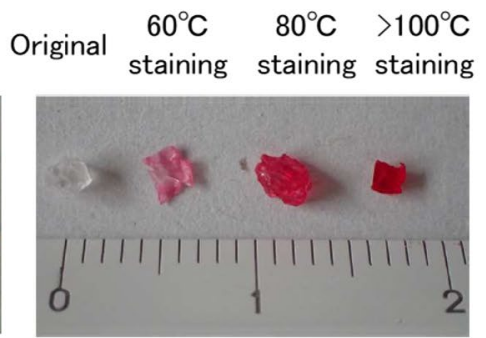

$\underline{\mathrm{PE}}$
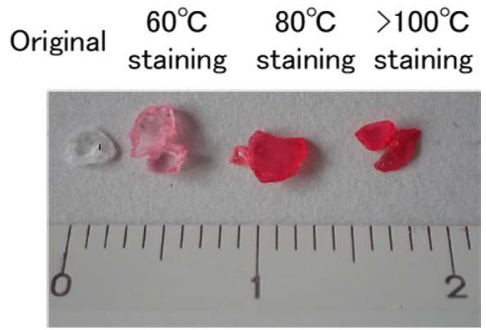

$\underline{\text { PS }}$

Figure 3. Results of the proposed method for staining at $60^{\circ} \mathrm{C}, 80^{\circ} \mathrm{C}$, and $105^{\circ} \mathrm{C}$ for $20 \mathrm{~min}$.

temperatures of $60^{\circ} \mathrm{C}, 80^{\circ} \mathrm{C}$, and $105^{\circ} \mathrm{C}$ for $20 \mathrm{~min}$ are shown in Fig. 3. All types of plastics could be stained, and the increase in staining intensity depended on the staining temperature. PE and PS were almost completely stained at the $80^{\circ} \mathrm{C}$ condition. However, $\mathrm{PP}$ was almost completely stained only at the $>100^{\circ} \mathrm{C}$ condition. These results suggest that the staining temperature can affect the staining intensity and be used to roughly classify the plastic species. The possibility of roughly classifying plastic species only based on their staining temperature $\left(60^{\circ} \mathrm{C}, 80^{\circ} \mathrm{C}\right.$, and $\left.>100^{\circ} \mathrm{C}\right)$ without a chemical analytical machine is one of the advantages of the proposed method.

In the third experiment, the influence of the staining process (chemical or thermal effect) for typical microplastics (PP) was investigated using attenuated total reflection-Fourier-transform infrared spectroscopy (ATRFTIR) (FT/IR-6600, Jasco, Japan). The ATR-FTIR results are shown in Fig. 4. The ATR spectra of each sample were quite similar, and the proposed staining method was not affected by the ATR-FTIR analysis. The results show that the proposed staining method can retain the original state of the plastic without affecting its chemical properties and does not affect the results of additional analyses such as ATR-FTIR.

In the final experiment, the staining results were found to be consistent across all three replicates for all fractions, where PP, PE, and PS were stained with 1:10 and 1:20 diluted staining solvents. The results of staining with the 1:10 diluted staining solvent is shown in Fig. 5. In the final experiment, the 1:20 diluted staining solvent sample was not bright, and it was difficult to identify the sand particle-contaminated sample. Moreover, the resulting colors were light compared with those of the first experiment (Fig. 2a). However, red color can be used 

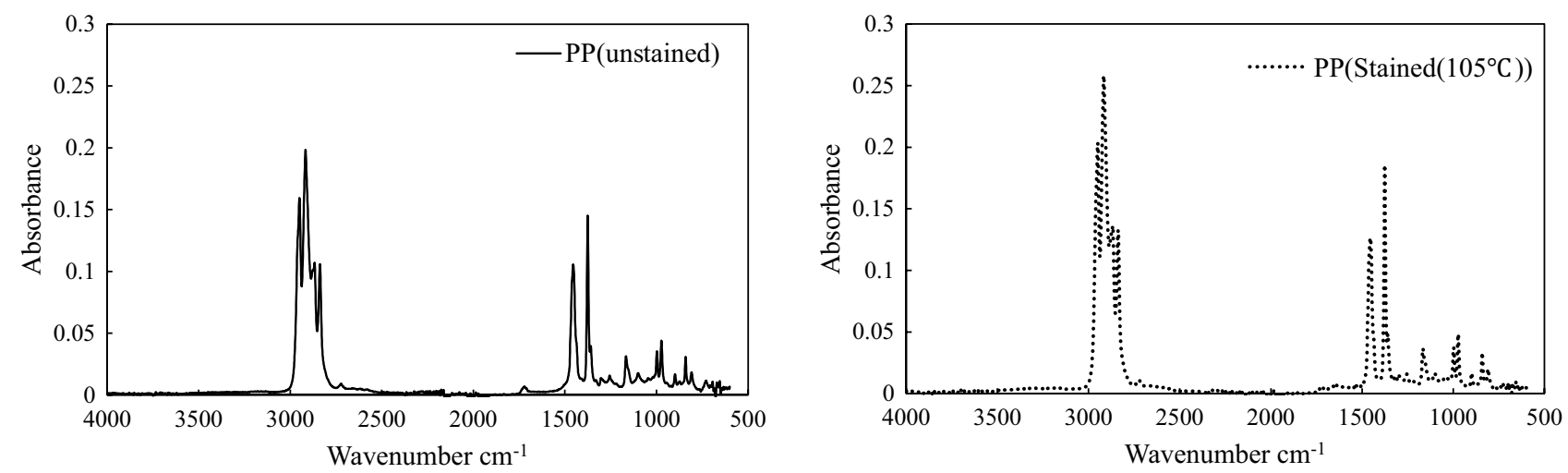

Figure 4. ATR spectra of unstained and stained PP.

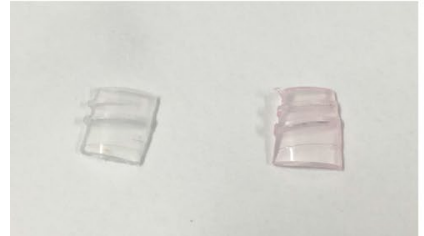

Original Stained

$\underline{P P}$

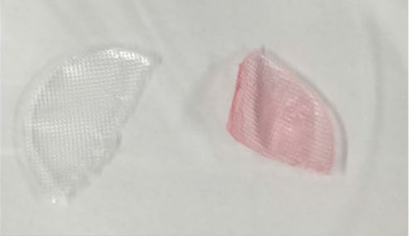

Original Stained $\underline{\mathrm{PE}}$

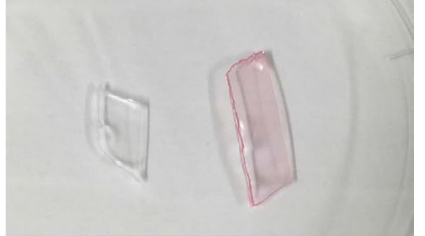

Original Stained

$\underline{\mathrm{PS}}$

Figure 5. Results of staining with 1:10 diluted staining solvent for polypropylene (PP), polyethylene (PE), and polystyrene (PS).

A

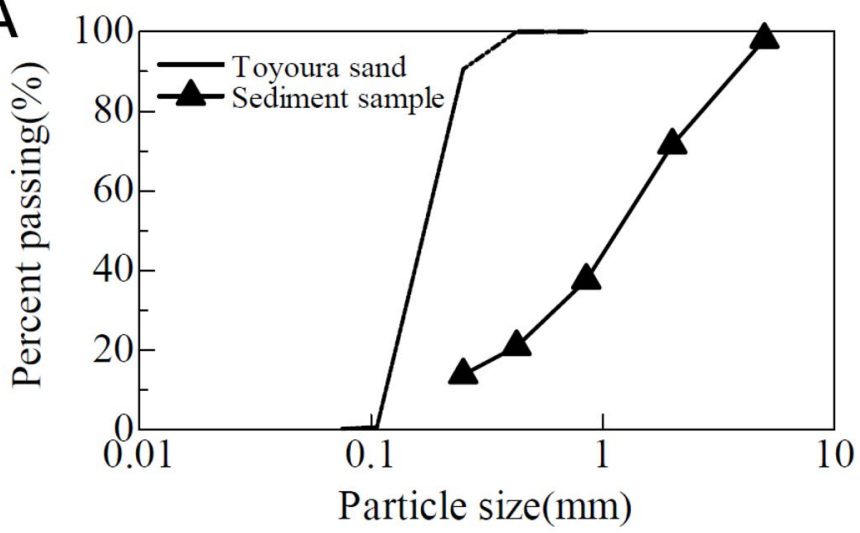

B

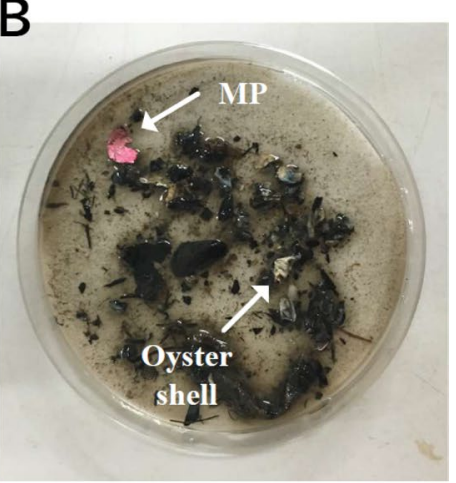

Figure 6. Results of staining with (A) undiluted staining solvent for polypropylene (PP), (B) 1:10 diluted staining solvent for polypropylene (PP), polyethylene (PE), and polystyrene (PS).

to identify microplastics contaminated with natural beach sand using the naked eye and microscopic observations. However, other polymers such as polytetrafluoroethylene (PTFE) were not stained with the diluted staining solvents at the same conditions. PTFE requires high temperatures and high pressures for staining.

Staining marine sediment samples using the sieving process. The particle size of dredged sediments in our study ranged from $0.106 \mathrm{~mm}$ to $>2 \mathrm{~mm}$ (mean [D50] $=1.16 \mathrm{~mm}$ ). Figure $6 \mathrm{~A}$ shows the particle distribution curve from dredged sediments and Toyoura sand (Japanese standard sand). The particles in the dredged sediments are larger than those in Toyoura sand (ranging from 0.1 to $<1 \mathrm{~mm}$ ) possibly because the sediments at Shin-Minato port originated from oyster shells and other human-related wastes and are likely to contain a wider range of microplastics/fibers. The red color staining solvent stained the large microplastic particles $(>5.0 \mathrm{~mm})$ in the sieved sediment sample (Fig. 6B). Many large particles are mixed with crushed shells coated with small substances such as clay or biofilms. The results of the staining of air-dried sediments (fractions 1-6) 


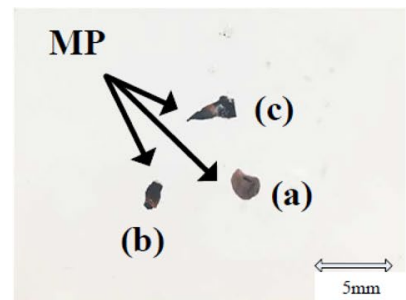

A(Fraction 1)

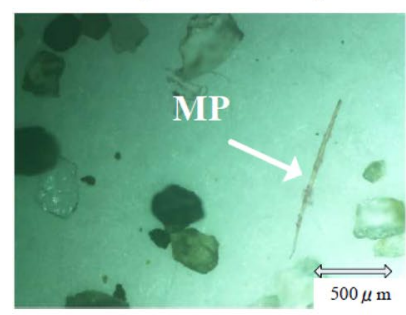

$\mathrm{D}$ (Fraction 4)

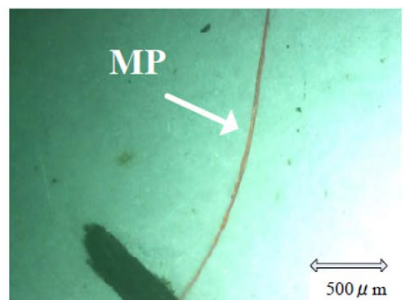

$\mathrm{B}($ Fraction 2)

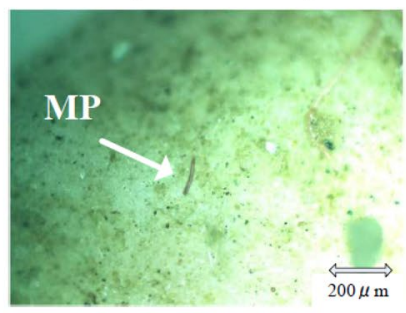

$\mathrm{E}($ Fraction 5)

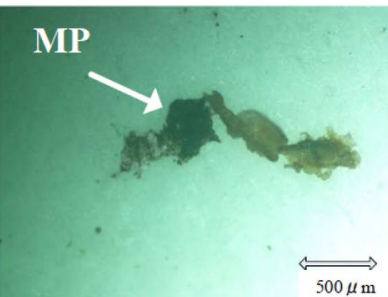

C(Fraction 3)

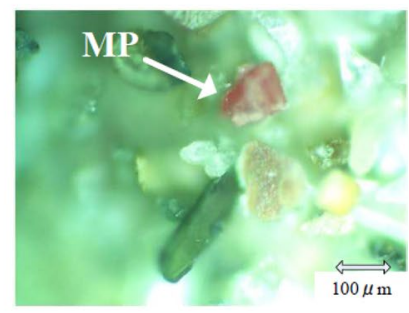

$\mathrm{F}($ Fraction 6)

Figure 7. Microplastics (MP) from the sediment samples were stained and visually observed (fractions 1-6) unaided and using a microscope (fractions 2-6). (A) fraction 1, particles $>2 \mathrm{~mm}$, photographed using an ana5100 Sony camera, (B) fraction 2, particle size $0.85-2 \mathrm{~mm},(\mathbf{C})$ fraction 3, particle size $0.42-0.85 \mathrm{~mm}$, (D) fraction 4, particle size $0.25-0.42 \mathrm{~mm}$, (E) fraction 5, particle size $0.106-0.25 \mathrm{~mm}$, and (F) fraction 6, particle size $<0.106 \mathrm{~mm}$.
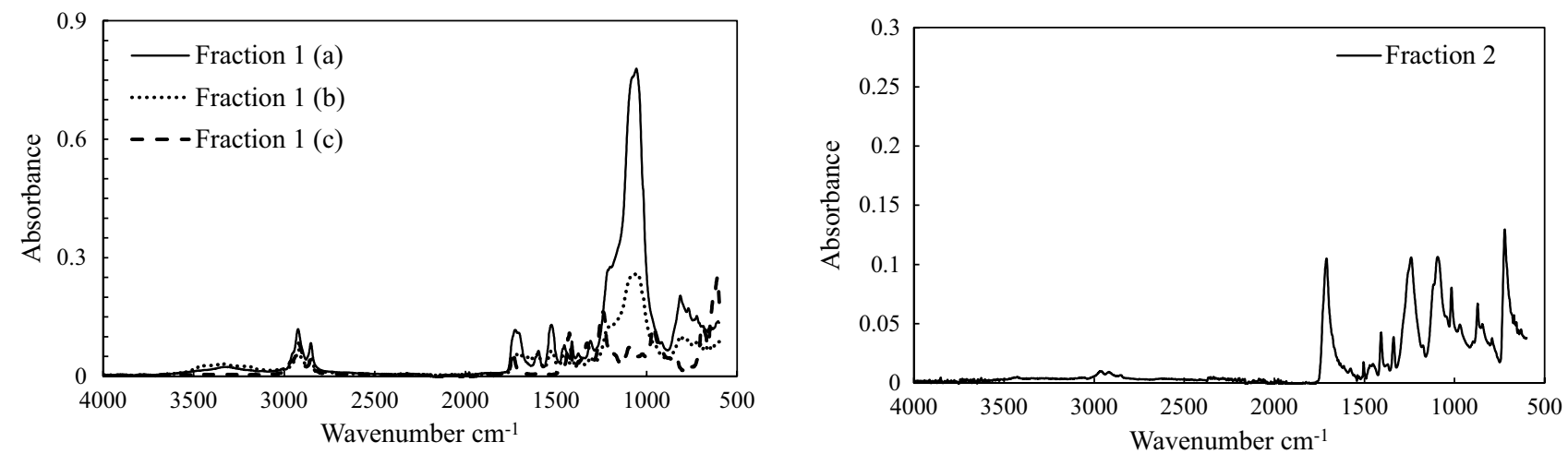

Figure 8. ATR spectra of fractions 1 and 2.

using our proposed method are shown in Fig. 7. The staining process generated small particles from substances coating the sample surface, which generally made the samples turbid and identification of the microplastics difficult. However, despite this turbidity, the proposed method can be used to easily identify plastics sized $>5 \mathrm{~mm}$ that are mixed with shiny materials such as shells (Fig. 6B).

The stained and unstained samples were analyzed using ATR-FTIR to classify the microplastics. The results of ATR-FTIR analyses indicated that the red-stained samples were PP. The white-stained samples could not be identified. These results indicate that the proposed method can be used to easily distinguish between plastic debris and inorganic substances.

The results of the microplastic classification using our proposed method are shown in Fig. 7A. The particles of fraction $1(>2.0 \mathrm{~mm})$ could be visually identified and were photographed using a normal camera ( $\alpha 5100$ Sony, Japan). Microplastics in this fraction originated from fragmented debris of daily necessities, such as medical press through pack sheets and styrene foams. To observe the particles of fractions 2-6 (Fig. 7B-F), a microscope (BHM series, Olympus Japan) with a charge-coupled device camera (EL310, Wraymer) was used. These fractions mostly contained small-sized particles such as fiber dust and crushed materials from daily waste and were detectable after staining (Fig. 7B-E). The particles of fraction $6(<0.106)$ were cube-shaped and stained red (Fig. 7F). The source of these small particles was identified as contamination from self-precipitated crystals from the staining solvent solution and was separate from the original microplastics or microfibers from the sediment.

To evaluate the accuracy of the proposed method, ATR-FTIR analysis was performed to identify the plastic species stained in fractions 1 and 2. The results of the ATR-FTIR analysis are shown in Fig. 8.

The fraction 1(a) and (b) samples are classified as slow-release fertilizers. The slow-release fertilizer material is based on the composite of polyurethane and inorganic substances such as talc. The fraction 1(c) sample was 


\begin{tabular}{|l|l|l|}
\hline Fraction number & Particle size $(\boldsymbol{\mu m})$ & Number of detections \\
\hline 1 & $\sim 2000$ & 2 \\
\hline 2 & $2000-850$ & 2 \\
\hline 3 & $850-420$ & 3 \\
\hline 4 & $420-250$ & 3 \\
\hline 5 & $250-106$ & 2 \\
\hline 6 & $106-75$ & 5 \\
\hline
\end{tabular}

Table 2. Number of microplastics detected from the dredged sediment samples.

classified as similar to PVC and included materials used in our daily lives. The fraction 2 sample, which included plastic fiber, was classified as PET, which is used in clothing fabrics.

All the samples stained using the proposed method were classified as a certain type of plastic, confirming the effectiveness of the proposed method.

The number of microplastics detected from the dredged sediment with sieving for each fraction is shown in Table 2. Almost the same numbers of plastics were detected irrespective of the fraction. This result indicates that plastics with a wide range of particle sizes are homogeneously deposited in shallow marine sediments.

\section{Discussion}

Visualizing microplastics obtained from dredged sediments is vital for studying their impact on the marine ecosystem. Currently, low-cost and easy detection methods to study the accumulation of microplastics in the environment are available ${ }^{37}$. A tracing method that can be used to visualize fluorescent microplastics using a general industrial ultraviolet flashlight has been reported ${ }^{38}$. However, it can only detect a limited number of microplastic types and cannot be used to identify nonfluorescent microplastics in the environment. Moreover, conventional methods based on specific gravity separations use saline water, which hinders the separation of biofilm coatings or clay aggregate microplastics from actual dredged marine sediments.

Therefore, it is necessary to develop separation and identification methods that are nontoxic, easy to perform, and can efficiently detect many types of microplastics under natural conditions, which can be applied to contaminated microplastics without the use of any specific equipment.

In this study, we developed a technique to isolate, stain, and detect (and roughly classify) microplastics from sediment samples that are derived from the environment. This combined method that involved staining and sieving processes can be used to separate microplastic particles based on their size and type and is in compliance with geotechnical industrial methods and standards (JGS ${ }^{30,31}, \mathrm{ISO}^{32,33}, \mathrm{EN}^{34}$, and $\mathrm{ASTM}^{35,36}$ ).

The target of the proposed method is microplastic contaminated sediment which contains daily and agricultural use plastics such as chemical fertilizer, laundry drainage mixed with waste textiles, etc. This proposed method has several advantages. First, it employs basic geotechnical or geological equipment with nontoxic reagents, which are available in most geological engineering fields. It can also be combined with microscopy, enabling the detection of small-sized microplastics. Second, it can be applied to ground and soil contamination and other construction and environmental industries during implementation in industrial projects. Third, the proposed method can be completed in approximately $1 \mathrm{~h}$.

Staining solvent and staining of different types of plastics. It is important to select a suitable staining color solvent from commercially based anthraquinone and azo dyes for staining sediment and particle mixes. Azo dyes can stain both natural and synthetic textile products, and their staining procedure is simple ${ }^{39}$. In this study, we investigated the efficiency of the staining color solvent under different dilutions and showed that diluting the solvent leads to a weaker staining result. Moreover, red-stained microplastics mixed with sediments were more visible than microplastics stained with other colors; therefore, we used the red stain in our experiments. The solubility of the dye is an important parameter in staining ${ }^{40}$, and our findings show that it is essential to adjust the concentration of the staining solvent for various plastics types before the experiments and field application.

The testing procedure of the proposed method is as follows: (1) wet sieving processes are applied to dredged sediments using standard methods (JGS, ISO, ASTM, EN, etc.), (2) red-colored staining solvent is diluted tenfold with distilled water and filtered through a $0.25-\mathrm{mm}$ membrane, (3) the sieved sediments are mixed with diluted staining solvents and heated to $105^{\circ} \mathrm{C}$ for $20 \mathrm{~min}$, and (4) after cooling, the sample is visually observed unaided and also using an optical microscope.

The azo dye-based staining solvent can be used to roughly classify different types of plastics according to the staining temperature. The relationship between the type of plastic and staining temperature under atmospheric pressure conditions is shown in Table 1.

The possibility of roughly classifying plastic species based on only their staining temperature $\left(60{ }^{\circ} \mathrm{C}, 80^{\circ} \mathrm{C}\right.$, and $>100^{\circ} \mathrm{C}$ ) without a chemical analytical machine is one of the advantages of our proposed method.

However, our method failed to stain fluoride polymer microplastics, indicating that our protocol may not be successful in detecting all types of microplastics under atmospheric pressure. We could stain PTFE under high pressures and temperatures that are similar to autoclave sterilization conditions $\left(121^{\circ} \mathrm{C}\right.$ and $\left.0.07 \mathrm{MPa}\right)$, but the result was not reliable due to the irregular staining pattern. 
Staining field sediment samples using the sieving process. Identifying small particles is important in the study of marine ecosystems because those are available to benthic microorganisms and can be transferred to higher food chain levels through ingestion ${ }^{3}$. The proposed method can be used to detect microplastics such as those with biofilm coatings or aggregates with other substances from dredged sediments more easily than other available techniques. ATR-FTIR analysis could identify the red-stained microplastics (PP) but failed to detect white-stained particles. This positive result implies that the proposed method can be used to visually classify the types of microplastics, contrary to the other available methods of microplastic observation ${ }^{41}$. Moreover, the smaller particles in fractions 2-5 were stained successfully and more efficiently than that using other tracing methods such as Nile red and fluorescence staining ${ }^{37,42}$.

The proposed method combined with sieving and staining can be used to selectively identify different types of plastics from seabed sediments using a few simple operations.

\section{Conclusions}

In this study, microplastic-contaminated sediments close to the mouth of rivers or estuaries were examined using a combination of a new staining procedure and conventional geotechnical equipment. This proposed method uses a nontoxic azo dye that is safe and easy to apply and can be used by geotechnical/environmental engineering firms. It can also be taught to students in primary elementary and junior high schools. Laboratory tests using artificial plastics mixed with Toyama sand indicate that the best staining solvent color is red. When actual dredged sediments were tested, the proposed method allowed unaided visual detection of large-sized nano/microplastics and the detection of smaller particles with the use of an optical microscope. In summary, wet sieving combined with staining can easily distinguish microplastics in sediments. Moreover, particles larger than $2.0 \mathrm{~mm}$ can be observed with the naked eye, even when the sample is turbid, and particles ranging from 0.1 to $<2.0 \mathrm{~mm}$ can be observed using a microscope. The method can also distinguish particle types. This study is significant because a method that is affordable, easy, and can efficiently analyze microplastics in sediments was developed. However, additional experiments under various temperatures and with various heating durations are required to evaluate this method to determine optimal staining conditions. In addition, we will use sediments collected from a variety of geographic locations and from different depths to further test the efficiency of our method. Finally, we will combine artificial intelligence screening methods with the proposed method of staining photos to identify the microplastics based on shape and color information. The final goal of this research is to establish easy screening methods without the use of specific instruments such as TGA-DTA and ATR-FTIR and promote primary or secondary grade environmental education.

\section{Materials and methods}

Staining color and staining of different plastic types. A staining solvent using nontoxic anthraquinone and azo-based disperse dyes was used in the experiment (Murakami Corp, Kyoto Japan). This solvent included the four colors (yellow, red, blue and green, Fig. 2a). First, the major microplastic source, PE, was stained with the basic four colors, which were checked with staining intensity without soils. The four colored PP samples were mixed with natural beach sand from Toyama Bay, Japan, and their visibility was evaluated. In the second experiment, three types of plastics were included in the staining process with undiluted red staining solvent at three temperatures, and the effect of the staining temperature was assessed, which can be used to roughly classify plastic species. The optimal staining temperature of the three types of plastics is shown in Table 1 . The classification of microplastic species with the staining process depends on the staining temperature: $60^{\circ} \mathrm{C}$ to $80^{\circ} \mathrm{C}$ for PE and $80^{\circ} \mathrm{C}$ to $>100^{\circ} \mathrm{C}$ for PP and PS. In the second experiment, a heat block (dry bath) machine (HDB-2N, As one, Japan) set to three temperature conditions was used to heat the samples for $20 \mathrm{~min}$.

The effect of the proposed staining method was assessed using ATR-FTIR, a conventional microplastic detection method. Two samples, i.e., the original sample and $105^{\circ} \mathrm{C}$-stained PP sample, were evaluated using ATRFTIR (FT/IR-6600, Jasco, Japan).

Finally, the selected staining solvent color is red that applied the recommended dilutions, 1:10 and 1:20 for this experiments, respectively, to stain PP (specific gravity $=0.91$ ), PE (specific gravity $=0.92$ ) and PS (specific gravity $=1.05$ ) pellets (Sanplatec Corp., Japan). The selected staining solvent can selectively stain various microplastics, including PP, PE, and PS, under multiple staining temperatures. Three types of microplastics were selected to determine the efficacy of the staining process. In the final experiment, a heat block (dry bath) machine (HDB-2 N, As one, Japan) set to a maximum temperature of $105^{\circ} \mathrm{C}$ was used to heat the samples for $20 \mathrm{~min}$, and the staining efficiency was determined using the naked eye, which will define the reasonable dilution rate of the proposed method such as non-dilution, 1:10 or 1:20.

Staining field sediment samples using the sieving process. A sediment sample was collected using an Eckman barge bottom sampler (Rigo, Japan) from Shin-Minato port yard at Toyama, Japan (GPS coordinates: $\mathrm{N} 36^{\circ} 46^{\prime} 15.8^{\prime \prime}$, E137 $05^{\prime} 46.8^{\prime \prime}$; depth from sea surface: $2.8 \mathrm{~m}$ ).

The sediment sample was sieved into six fractions: (1) $>2.0 \mathrm{~mm}$, (2) $0.85-2.0 \mathrm{~mm}$, (3) $0.42-0.85 \mathrm{~mm}$, (4) $0.25-0.42 \mathrm{~mm},(5) 0.106-0.25 \mathrm{~mm}$, and $(6)<0.106 \mathrm{~mm}$. Three replicates were analyzed from each fraction. Fraction $1(>2.0 \mathrm{~mm})$ was rinsed with tap water and placed in a $50-\mathrm{mL}$ glass beaker. The beaker was filled with staining solvent to cover the top of the sample and was kept at $105^{\circ} \mathrm{C}$ for $20 \mathrm{~min}$. The applicability of the proposed method was validated by analyzing stained samples from fractions 1 and 2 using ATR-FTIR analysis (Nicolet Summit, ThermoFisher), and the plastic species were confirmed. In ATR-FTIR, an infrared spectra database is used to accurately determine the type of plastic ${ }^{43}$.

The remaining fractions were used in the following steps. We placed $0.2 \mathrm{~g}$ of each fraction sample in individual 15-mL glass test tubes. Then, $10 \mathrm{~mL}$ of tenfold diluted red staining solvent was added to each test tube and mixed 
with the sample using a vortex mixer (Kenis, Japan). After mixing, the test tube was covered with an aluminum cap to prevent contamination with microfibers from the room air. Staining was conducted at $105^{\circ} \mathrm{C}$ for $20 \mathrm{~min}$. Immediately after the heating process, the samples were rinsed with tap water three times. The samples were rinsed gently and carefully to avoid losing the floating types of microplastics. At the end of this process, the dye remaining on the microplastic surface was used for additional analyses. Rinsed microplastic mixed sediments were filtered using glass fiber filters with a vacuum filtration machine. After the vacuum filtration, the glass fiber filters were observed under an optical microscope (BHM series, Olympus Japan) to detect the microplastics or fibers.

\section{Data availability}

All data generated or analyzed during this study are included in this published article.

Received: 14 July 2021; Accepted: 4 October 2021

Published online: 19 October 2021

\section{References}

1. Cole, M., Lindeque, P., Halsband, C. \& Galloway, T. S. Microplastics as contaminants in the marine environment: A review. Mar. Pollut. Bull. 62, 2588-2597. https://doi.org/10.1016/j.marpolbul.2011.09.025,22001295 (2011).

2. Cauwenberghe, V. L., Vanreusel, A., Mees, J. \& Janssen, C. R. Microplastic pollution in deep-sea sediments. Environ. Pollut. 182, 495-499. https://doi.org/10.1016/j.envpol.2013.08.013,24035457 (2013).

3. Cole, M. et al. Microplastic ingestion by zooplankton. Environ. Sci. Technol. 47, 6646-6655. https://doi.org/10.1021/es400663f,23692 270 (2013).

4. Rodrigues, J. P., Duarte, A. C., Santos-Echeandía, J. \& Rocha-Santos, T. Significance of interactions between microplastics and POPs in the marine environment: A critical overview. TrAC Trends Anal. Chem. 111, 252-260. https://doi.org/10.1016/j.trac.2018. 11.038 (2019).

5. Brennecke, D., Duarte, B., Paiva, F., Caçador, I. \& Canning-Clode, J. Microplastics as vector for heavy metal contamination from the marine environment. Estuar Coast Shelf Sci. 178, 189-195. https://doi.org/10.1016/j.ecss.2015.12.003 (2016).

6. Martins, I., Rodríguez, Y. \& Pham, C. K. Trace elements in microplastics stranded on beaches of remote islands in the NE Atlantic. Mar. Pollut. Bull. 156, 111270. https://doi.org/10.1016/j.marpolbul.2020.111270 (2020).

7. Woodall, L. C. et al. The deep sea is a major sink for microplastic debris. R. Soc. Open Sci. 1, 140317. https://doi.org/10.1098/rsos. 140317 (2014).

8. Alomar, C., Estarellas, F. \& Deudero, S. Microplastics in the Mediterranean Sea: Deposition in coastal shallow sediments, spatial variation and preferential grain size. Mar. Environ. Res. 115, 1-10. https://doi.org/10.1016/j.marenvres.2016.01.005,26803229 (2016).

9. Wright, S. L., Thompson, R. C. \& Galloway, T. S. The physical impacts of microplastics on marine organisms: A review. Environ. Pollut. 178, 483-492. https://doi.org/10.1016/j.envpol.2013.02.031,23545014 (2013).

10. Fendall, L. S. \& Sewell, M. A. Contributing to marine pollution by washing your face: Microplastics in facial cleansers. Mar. Pollut. Bull. 58, 1225-1228. https://doi.org/10.1016/j.marpolbul.2009.04.025,19481226 (2009).

11. Andrady, A. L. Microplastics in the marine environment. Mar. Pollut. Bull. 62, 1596-1605. https://doi.org/10.1016/j.marpolbul. 2011.05.030 (2011).

12. Pakula, C. \& Stamminger, R. Electricity and water consumption for laundry washing by washing machine worldwide. Energy Effic. 3, 365-382. https://doi.org/10.1007/s12053-009-9072-8 (2010).

13. Belzagui, F., Crespi, M., Álvarez, A., Gutiérrez-Bouzán, C. \& Vilaseca, M. Microplastics' emissions: Microfibers’ detachment from textile garments. Environ. Pollut. 248, 1028-1035. https://doi.org/10.1016/j.envpol.2019.02.059,31091635 (2019).

14. Ziajahromi, S., Drapper, D., Hornbuckle, A., Rintoul, L. \& Leusch, F. D. L. Microplastic pollution in a stormwater floating treatment wetland: Detection of tyre particles in sediment. Sci. Total Environ. 713, 136356. https://doi.org/10.1016/j.scitotenv.2019.136356 (2020).

15. Fadare, O. O. \& Okoffo, E. D. Covid-19 face masks: A potential source of microplastic fibers in the environment. Sci. Total Environ. 737, 140279. https://doi.org/10.1016/j.scitotenv.2020.140279 (2020).

16. Klein, S., Worch, E. \& Knepper, T. P. Occurrence and spatial distribution of microplastics in river shore sediments of the rhinemain area in Germany. Environ. Sci. Technol. 49, 6070-6076. https://doi.org/10.1021/acs.est.5b00492,25901760 (2015).

17. Rummel, C. D., Jahnke, A., Gorokhova, E., Kühnel, D. \& Schmitt-Jansen, M. Impacts of biofilm formation on the fate and potential effects of microplastic in the aquatic environment. Environ. Sci. Technol. Lett. 4, 258-267. https://doi.org/10.1021/acs.estlett.7b001 64 (2017).

18. Claessens, M., Meester, S., Landuyt, V. L., Clerck, K. \& Janssen, C. R. Occurrence and distribution of microplastics in marine sediments along the Belgian coast. Mar. Pollut. Bull. 62, 2199-2204. https://doi.org/10.1016/j.marpolbul.2011.06.030,21802098 (2011).

19. Song, Y. K. et al. A comparison of microscopic and spectroscopic identification methods for analysis of microplastics in environmental samples. Mar. Pollut. Bull. 93, 202-209. https://doi.org/10.1016/j.marpolbul.2015.01.015,25682567 (2015).

20. Lenz, R., Enders, K., Stedmon, C. A., Mackenzie, D. M. A. \& Nielsen, T. G. A critical assessment of visual identification of marine microplastic using Raman spectroscopy for analysis improvement. Mar. Pollut. Bull. 100, 82-91. https://doi.org/10.1016/j.marpo lbul.2015.09.026,26455785 (2015).

21. Majewsky, M., Bitter, H., Eiche, E. \& Horn, H. Determination of microplastic polyethylene (PE) and polypropylene (PP) in environmental samples using thermal analysis (TGA-DSC). Sci. Total Environ. 568, 507-511. https://doi.org/10.1016/j.scitotenv.2016. $06.017,27333470(2016)$.

22. Shim, W. J., Song, Y. K., Hong, S. H. \& Jang, M. Identification and quantification of microplastics using Nile red staining. Mar. Pollut. Bull. 113, 469-476. https://doi.org/10.1016/j.marpolbul.2016.10.049,28340965 (2016).

23. Lv, L. et al. A simple method for detecting and quantifying microplastics utilizing fluorescent dyes - safranine $\mathrm{T}$, fluorescein isophosphate, Nile red based on thermal expansion and contraction property. Environ. Pollut. 255, 113283. https://doi.org/10. 1016/j.envpol.2019.113283 (2019).

24. Cauwenberghe, V. L., Devriese, L., Galgani, F., Robbens, J. \& Janssen, C. R. Microplastics in sediments: A review of techniques, occurrence and effects. Mar. Environ. Res. 111, 5-17. https://doi.org/10.1016/j.marenvres.2015.06.007 (2015).

25. Isobe, A. et al. An interlaboratory comparison exercise for the determination of microplastics in standard sample bottles. Mar. Pollut. Bull. 146, 831-837. https://doi.org/10.1016/j.marpolbul.2019.07.033,31426225 (2019).

26. Uddin, S., Fowler, S. W., Saeed, T., Naji, A. \& Al-Jandal, N. Standardized protocols for microplastics determinations in environmental samples from the Gulf and marginal seas. Mar. Pollut. Bull. 158, 111374. https://doi.org/10.1016/j.marpolbul.2020.111374 (2020). 
27. Vermeiren, P., Muñoz, C. \& Ikejima, K. Microplastic identification and quantification from organic rich sediments: A validated laboratory protocol. Environ. Pollut. 262, 114298. https://doi.org/10.1016/j.envpol.2020.114298 (2020).

28. Coppock, R. L., Cole, M., Lindeque, P. K., Queirós, A. M. \& Galloway, T. S. A small-scale, portable method for extracting microplastics from marine sediments. Environ. Pollut. 230, 829-837. https://doi.org/10.1016/j.envpol.2017.07.017 (2017).

29. Ankley, G. T., Di Toro, D. M., Hansen, D. J. \& Berry, W. J. Technical basis and proposal for deriving sediment quality criteria for metals. Environ. Toxicol. Chem. 15, 2056-2066. https://doi.org/10.1002/etc.5620151202 (1996).

30. Japanese Geotechnical Society (JGS) 0131 (JIS A1204). Test method for particle size distribution of soils (2009).

31. Japanese Geotechnical Society JGS 0121(JIS A1203). Test method for water content of soils (2009).

32. BS ISO 11277: Soil quality. Determination of particle size distribution in mineral soil material. Method by sieving and sedimentation (2009).

33. BS ISO 1377:Part 2: Clause 3.2: Determination of the moisture content of soils (1990).

34. BS EN 933-2: Tests for geometrical properties of aggregates. Determination of particle size distribution. Test sieves, nominal size of apertures (2020).

35. ASTM D6913/D6913M - 17: Standard Test Methods for Particle-Size Distribution (Gradation) of Soils Using Sieve Analysis (2004).

36. ASTM D2216 - 19: Standard Test Methods for Laboratory Determination of Water (Moisture) Content of Soil and Rock by Mass (2019).

37. Maxwell, S. H., Melinda, K. F. \& Matthew, G. Counterstaining to separate Nile red-stained microplastic particles from terrestrial invertebrate biomass. Environ. Sci. Technol. 54, 5580-5588. https://doi.org/10.1021/acs.est.0c00711 (2020).

38. Ehlers, S. M., Maxein, J. \& Koop, J. H. E. Low-cost microplastic visualization in feeding experiments using an ultraviolet lightemitting flashlight. Ecol. Res. 35, 265-273. https://doi.org/10.1111/1440-1703.12080 (2020).

39. Karakolis, E. G., Nguyen, B., You, J. B., Rochman, C. M. \& Sinton, D. Fluorescent dyes for visualizing microplastic particles and fibers in laboratory-based studies. Environ. Sci. Technol. Lett. 6, 334-340. https://doi.org/10.1021/acs.estlett.9b00241 (2019).

40. Penthala, R. et al. Synthesis of azo and anthraquinone dyes and dyeing of nylon-6,6 in supercritical carbon dioxide. J. CO2 Util. 38, 49-58. https://doi.org/10.1016/j.jcou.2020.01.013 (2020).

41. Prata, J. C., Costa, J. P., Duarte, A. C. \& Rocha-Santos, T. Methods for sampling and detection of microplastics in water and sediment: A critical review. TrAC Trends Anal. Chem. 110, 150-159. https://doi.org/10.1016/j.trac.2018.10.029 (2019).

42. Hengstmann, E. \& Fischer, E. K. Nile red staining in microplastic analysis - proposal for a reliable and fast identification approach for large microplastics. Environ. Monit. Assess. 191, 612. https://doi.org/10.1007/s10661-019-7786-4,31489505 (2019).

43. Jung, M. R. et al. Validation of ATR FT-IR to identify polymers of plastic marine debris, including those ingested by marine organisms. Mar. Pollut. Bull. 127, 704-716. https://doi.org/10.1016/j.marpolbul.2017.12.061 (2018).

\title{
Acknowledgements
}

This research was partially funded by Japan Society for the Promotion of Science KAKENHI (Grant number: 17K18909, 19H02239). We are grateful to the Shiminato port authorities for field assistance.

\section{Author contributions}

T.H. conceptualized the research idea, conducted the experiments and data analysis, acquired funding and prepared the original draft of the manuscript. N.J. reviewed and validated the proposed method, contributed to writing, reviewing, and editing the manuscript.

\section{Competing interests}

The authors declare no competing interests.

\section{Additional information}

Correspondence and requests for materials should be addressed to T.H.

Reprints and permissions information is available at www.nature.com/reprints.

Publisher's note Springer Nature remains neutral with regard to jurisdictional claims in published maps and institutional affiliations.

\begin{abstract}
Open Access This article is licensed under a Creative Commons Attribution 4.0 International License, which permits use, sharing, adaptation, distribution and reproduction in any medium or format, as long as you give appropriate credit to the original author(s) and the source, provide a link to the Creative Commons licence, and indicate if changes were made. The images or other third party material in this article are included in the article's Creative Commons licence, unless indicated otherwise in a credit line to the material. If material is not included in the article's Creative Commons licence and your intended use is not permitted by statutory regulation or exceeds the permitted use, you will need to obtain permission directly from the copyright holder. To view a copy of this licence, visit http://creativecommons.org/licenses/by/4.0/.
\end{abstract}

(c) The Author(s) 2021 